\title{
A Novel Glycosyl Hydrolase Family $16 \beta$-Agarase from the Agar- Utilizing Marine Bacterium Gilvimarinus agarilyticus JEA5: the First Molecular and Biochemical Characterization of Agarase in Genus Gilvimarinus
}

\author{
Youngdeuk Lee ${ }^{1}$, Eunyoung Jo ${ }^{1}$, Yeon-Ju Lee ${ }^{2}$, Sachithra Amarin Hettiarachchi ${ }^{1,3}$, Gun-Hoo Park ${ }^{1}$, Su-Jin Lee ${ }^{1}$, \\ Soo-Jin $\mathrm{Heo}^{1,3}$, Do-Hyung Kang ${ }^{1,3 *}$, and Chulhong $\mathrm{Oh}^{1,3 *}$ \\ ${ }^{1}$ Korea Institute of Ocean Science and Technology, Jeju Special Self-Govering Province 63349, Republic of Korea \\ ${ }^{2}$ Korea Institute of Ocean Science and Technology, Ansan 15627, Republic of Korea \\ ${ }^{3}$ Department of Marine Biology, Korea University of Science and Technology, Jeju Special Self-Governing Province 63349, Republic of Korea
}

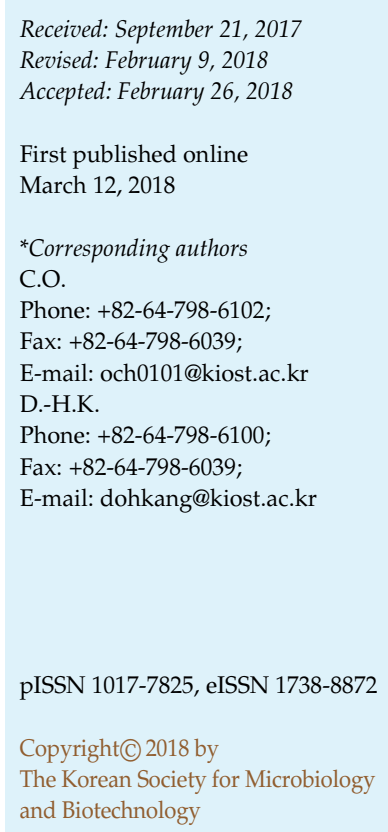

The agarase gene gaa16a was identified from a draft genome sequence of Gilvimarinus agarilyticus JEA5, an agar-utilizing marine bacterium. Recently, three agarase-producing bacteria, G. chinensis, G. polysaccharolyticus, and G. agarilyticus, in the genus Gilvimarinus were reported. However, there have been no reports of the molecular characteristics and biochemical properties of these agarases. In this study, we analyzed the molecular characteristics and biochemical properties of agarases in Gilvimarinus. Gaa16A comprised a 1,323-bp open reading frame encoding 441 amino acids. The predicted molecular mass and isoelectric point were $49 \mathrm{kDa}$ and 4.9, respectively. The amino acid sequence of Gaa16A showed features typical of glycosyl hydrolase family 16 (GH16) $\beta$-agarases, including a GH16 domain, carbohydrate-binding region (RICIN domain), and signal peptide. Recombinant Gaa16A (excluding the signal peptide and carbohydrate-binding region, rGaa16A) was expressed as a fused protein with maltose-binding protein at its N-terminus in Escherichia coli. rGaa16A had maximum activity at $55^{\circ} \mathrm{C}$ and $\mathrm{pH} 7.0$ and $103 \mathrm{U} / \mathrm{mg}$ of specific activity in the presence of $2.5 \mathrm{mM} \mathrm{CaCl}_{2}$. The enzyme hydrolyzed agarose to yield neoagarotetraose as the main product. This enzyme may be useful for industrial production of functional neoagaro-oligosaccharides.

Keywords: Gilvimarinus, agarase, neoagaro-oligosaccharides, cloning, overexpression

\section{Introduction}

Agar is a complex polysaccharide found in the cell walls of some red algae, and up to $70 \%$ of the algal cell wall can be made up of agar polymers [1]. Agarose and agaropectin are major components of agar [2]. Agarose contains D-galactose and 3,6-anhydro-L-galactose as its monomeric units, which are linked by alternating $\alpha-1,3-$ and $\beta-1,4$-glycosidic bonds [3]. The hydrolysis of agarose is accomplished by $\alpha$-agarase (E.C. 3.2.1.158) and $\beta$-agarase (E.C. 3.2.1.81). First, the $\alpha-1,3$ linkage of agarose is cleaved, resulting in agarooligosaccharides, and the $\beta-1,4$ linkage is then cleaved to generate neoagaro-oligosaccharides [2]. Most agarases that are currently being studied and utilized are $\beta$-agarases. On the basis of on amino acid sequence homology, $\beta$-agarases are classified into four families: glycoside hydrolase family 16 (GH16), GH50, GH86, and GH118 [4]. The reported biological and physiological functions of neoagaro-oligosaccharides, including their moisturizing effect on the skin [5], whitening effect on melanoma cells [6], macrophage stimulation [7], antitumor activity [8], prebiotic effects [9], and antibacterial activity [10], have increased their value while simultaneously broadening their applications in the food, cosmetic, and medical industries. 
The isolation of agar-degrading bacteria has been accomplished with different natural sources such as seawater, marine sediments, marine algae, marine mollusks, fresh water, and soil [2]. In microorganisms, many agarases have been reported from Agarivorans sp. [11], Alteromonas sp. [12], Pseudomonas sp. [13, 14], Vibrio sp. [15, 16], Pseudoalteromonas sp. [17], Bacillus sp. [18, 19], Microbulbifer sp. [20, 21], Saccharophagus sp. [22], Acinetobacter sp. [23], among others. Recently, Gilvimarinus chinensis [24], Gilvimarinus polysaccharolyticus [25], and Gilvimarinus agarilyticus [26] were described, and their agarolytic activity was reported. However, there have been no published reports that include the molecular and functional characterization of agarases from the Gilvimarinus genus. Previously, we isolated the agar-degrading bacterium Gilvimarinus agarilyticus JEA5 and reported its draft genome sequence [27]. In this study, we report the first molecular and biochemical characterization of agarase from the Gilvimarinus genus.

\section{Materials and Methods}

\section{Identification and Molecular Characterization of $\beta$-Agarase}

Previously, we reported that the agar-degrading bacterium G. agarilyticus JEA5 was isolated from Jeju Island, South Korea. We described identification of that strain using 16S rRNA and genome sequencing with next-generation sequencing (NGS) technology [27]. A putative agarase was identified with the Basic Local Alignment Search Tool algorithm [28] and designated Gaa16A.

The signal peptide of Gaa16A was predicted using the SignalP 4.1 server (http://www.cbs.dtu.dk/services/SignalP/) [29], and the percentage identity/similarity of this agarase against homologs was calculated with the EMBOSS Pairwise Sequence Alignment Tool (http://www.ebi.ac.uk/Tools/psa/) [30]. Active sites, catalytic sites, and functional domains were identified with the use of the following programs: NCBI Conserved Domains Database (CDD; http://www.ncbi.nlm.nih.gov/cdd/) [31], Simple Modular Architecture Research Tool (http://smart.embl-heidelberg.de/) [32], and the InterPro web program (http://www.ebi.ac.uk/ interpro) $[33,34]$.

\section{Cloning of Gaa16A}

To amplify the predicted agarase gene gaa16a, a primer set (Gaa16A-F and Gaa16A-R) was designed to bind the pMal-c2x site with $>15 \mathrm{bp}$ nucleotide coverage at the cloning site using the
pMal-c $2 x$ sequence. The primers are shown in Table 1. Polymerase chain reaction (PCR) amplification of the gaa16a gene was performed with LA Taq polymerase (TaKaRa, Japan). We removed the predicted signal sequences at the $\mathrm{N}$-terminus of Gaa16A, as well as the RICIN superfamily domain at the Cterminus. The pMal-c2x expression vector (New England Biolabs, UK) was digested, and the amplicons were digested with BamHI (TaKaRa, Japan) and SalI (TaKaRa, Japan) restriction enzymes at $37^{\circ} \mathrm{C}$ for $2 \mathrm{~h}$, following the manufacturer's instructions. The digested pMal-c2x expression vector was gel purified using the AccuPrep Gel Purification Kit (Bioneer, Korea). The Gaa16A PCR product was cloned into the digested $\mathrm{pMal}-\mathrm{c} 2 \mathrm{x}$ expression vector with the Ez-Fusion Cloning Kit (Enzynomics, Korea) following the manufacturer's protocol, and the recombinant plasmid was then transformed into Escherichia coli DH5 $\alpha$. The clone was purified using the AccuPrep Nano-Plus Plasmid Mini Extraction Kit (Bioneer, Korea) and then again transformed into the expression vector E. coli BL21 (DE3). Finally, the nucleotide sequence of the newly constructed recombinant plasmid was confirmed by sequencing (Macrogen, Korea).

\section{Overexpression and Purification of Recombinant Agarase}

E. coli BL21 (DE3) containing pMal-c2x-gaa16a was inoculated into $5 \mathrm{ml}$ of LB broth supplemented with ampicillin $(100 \mathrm{mg} / \mathrm{ml})$ and cultured overnight at $37^{\circ} \mathrm{C}$. The overnight culture was transferred into $250 \mathrm{ml}$ of fresh LB broth supplemented with ampicillin $(100 \mathrm{mg} / \mathrm{ml})$ and incubated with shaking at $37^{\circ} \mathrm{C}$ until the culture reached an optical density of 0.6 at $600 \mathrm{~nm}$. Isopropyl$\beta$-D-thiogalactoside was added to a final concentration of $1 \mathrm{mM}$. To overexpress the recombinant protein, the cultures were incubated at $37^{\circ} \mathrm{C}$ for $3 \mathrm{~h}$. Cells from the $250 \mathrm{ml}$ culture were pelleted by centrifugation at $1,800 \times g$ for $15 \mathrm{~min}$ and resuspended in $20 \mathrm{ml}$ of column buffer before storing at $-20^{\circ} \mathrm{C}$ overnight. Frozen cells were thawed on ice, sonicated, and centrifuged (13,000 $\times g, 20 \mathrm{~min}$, $4^{\circ} \mathrm{C}$ ). rGaa116A was purified from the supernatant using the pMal Protein Fusion \& Purification System (New England Biolabs, USA). Sodium dodecyl sulfate-polyacrylamide gel electrophoresis (SDS-PAGE) was performed to analyze the purified protein, and the protein concentration was determined using the BCA Protein Assay Reagent Kit (Thermo Fisher Scientific Inc., USA).

\section{Agarolytic Activity Assay}

The amount of reducing sugar was determined by a modified 3,5-dintrosalicylic acid method [17, 35] using D-galactose as the standard. The amount of enzyme required to produce $1 \mu \mathrm{mol}$ of reduced sugar per minute was defined as one unit of enzyme

Table 1. PCR primer set for amplification of the gaa16a gene without the RICIN domain-coding region.

\begin{tabular}{lll}
\hline Name & Sequence & Purpose \\
\hline gaa1-F & 5'-TTC AGA ATT CGG ATC GCC GAC TGG GAT AAC AC-3' & Gaa1 amplification without RICIN \\
gaa1-R & 5'-TTG CCT GCA GGT CGA CTA TTG ACG ACC TTT AAT GCT G-3' & Gaa1 amplification without RICIN \\
\hline
\end{tabular}


activity. Substrate was prepared using SeaKem LE Agarose (Lonza, Switzerland) dissolved in deionized water by boiling, and then cooled to $45^{\circ} \mathrm{C}$. The enzyme reaction mixture was prepared in a $200 \mu \mathrm{l}$ total volume containing $100 \mu \mathrm{l}$ of $1 \%$ agarose (final concentration $0.5 \%$ ), $95 \mu \mathrm{l}$ of the proper buffer, and $5 \mu \mathrm{l}$ of diluted recombinant enzyme. The optimum $\mathrm{pH}$ of rGaa16A was determined over a $\mathrm{pH}$ range of $3.0-10.0$ with intervals of $\mathrm{pH} 0.5$ at $50^{\circ} \mathrm{C}$ for 20 min. Citrate phosphate buffer ( $\mathrm{pH} 3.0-6.0)$, phosphate buffer $(\mathrm{pH}$ 6.0-8.0), and glycine- $\mathrm{NaOH}$ buffer $(\mathrm{pH} 8.0-10.0)$ were used for various $\mathrm{pH}$ conditions. The optimum temperature for the enzyme activity of rGaa16A was determined by monitoring the relative activity at temperatures ranging (in $5^{\circ} \mathrm{C}$ intervals) from $40^{\circ} \mathrm{C}$ to $75^{\circ} \mathrm{C}$ at the optimum $\mathrm{pH}$ of 8.0 for $20 \mathrm{~min}$. The thermostability of rGaa16A was measured at $50^{\circ} \mathrm{C}$ and $\mathrm{pH} 8.0$ after preincubation at temperatures of $40^{\circ} \mathrm{C}, 50^{\circ} \mathrm{C}$, and $60^{\circ} \mathrm{C}$ for 30,60 , and $90 \mathrm{~min}$. The sensitivities of rGaa16A to various metal ion salts and chelators were determined under optimal $\mathrm{pH}$ and temperature conditions in reaction mixtures supplemented with $2.5 \mathrm{mM} \mathrm{CaCl}_{2}, \mathrm{CuSO}_{4}$, EDTA, $\mathrm{FeSO}_{4}, \mathrm{KCl}, \mathrm{MgSO}_{4}, \mathrm{MnCl}_{2}, \mathrm{NaCl}$, or $\mathrm{ZnSO}_{4}$.

\section{Hydrolytic Product Analysis}

The hydrolytic product of agarose from the recombinant enzyme rGaa16A was identified using thin-layer chromatography (TLC). Enzymatic hydrolysis of agarose was carried out at $45^{\circ} \mathrm{C}$ for $1 \mathrm{~h}$ in distilled water containing $10 \mu \mathrm{l}$ of rGaa16A and $90 \mu \mathrm{l}$ of $0.5 \%$ agarose. The mixture was applied to a silica gel 60 TLC plate (Merck, Germany) and developed with $n$-butanol:acetic acid: $\mathrm{dH}_{2} \mathrm{O}$ $(2: 1: 1(\mathrm{v} / \mathrm{v}))$. Spots were visualized by spraying with an orcinol dip reagent $(80 \mathrm{mg}$ of orcine monohydrate dissolved in $160 \mathrm{ml}$ of acetone; $8 \mathrm{ml}$ of sulfuric acid then added), followed by heating at $100^{\circ} \mathrm{C}$ for $10 \mathrm{~min}$. D-(+)-Galactose (Riedel de Haen, Germany), neoagarobiose (Carbosynth, UK), neoagarotetraose (Carbosynth, UK), and neoagarohexaose (Carbosynth, UK) were used as standards.

\section{Results}

\section{Molecular Characterization of Gaa16A}

The nucleotide and amino acid sequences of Gaa16A have been submitted to NCBI under accession number
KP716979. gaa16a has a 1,323-bp open reading frame that encodes 441 amino acids. The molecular mass and isoelectric point were predicted to be $49 \mathrm{kDa}$ and 4.9 , respectively. A signal sequence is located in the $\mathrm{N}$-terminal region (amino acid positions 1-22). Conserved GH16 and RICIN superfamily (ricin-type beta-trefoil; carbohydrate-binding domain formed from presumed gene triplication) sequences were identified at amino acid positions 19-289 and 307-440, respectively. We assumed that the catalytic residues of Gaa16A were 145-Glu, 147-Asp, and 150-Glu in the GH16 catalytic domain. The predicted calcium-binding sites were observed at the amino acid positions 20-Asp, 46-Asn, and 283-Asp. Gaa16A showed the highest identity with hypothetical proteins from G. chinensis (GenBank Accession No. WP_020208752.1) and G. polysaccharolyticus (WP_049721016.1), as well as a predicted agarase from Pseudomonas sp. ND137 (BAB79291.1) (Table 2). However, there are no published characterization or overexpression studies on these proteins. These sequences, including Gaa16A, showed less than $71 \%$ similarity with characterized agarases, such as those from Catenovulum agarivorans YM01 and Agarivorans sp. LQ48.

\section{Expression and Purification of Recombinant Agarase}

Maltose binding protein (MBP)-tagged recombinant Gaa16A protein (with the RICIN superfamily domain removed) was overexpressed in E. coli (BL21) and purified using the pMAL Protein Fusion and Purification System. The purified recombinant protein was identified by the strong band on the SDS-PAGE gel (Fig. 1), which was similar to the predicted molecular mass ( $33 \mathrm{kDa}$ with $42 \mathrm{kDa}$ of MBP).

\section{Enzymatic Characterization of Recombinant Agarase}

The recombinant agarase rGaa16A showed its highest agarolytic activity at $55^{\circ} \mathrm{C}$, and over $80 \%$ of its activity remained at $65^{\circ} \mathrm{C}$ (Fig. 2A); however, its activity was dramatically decreased to less than $20 \%$ at $70^{\circ} \mathrm{C}$. The

Table 2. Identity and similarity of rGaa16A compared with amino acid sequences of other predicted agarase sequences and characterized agarases.

\begin{tabular}{|c|c|c|c|c|c|}
\hline & $\begin{array}{c}\text { Identity } \\
(\%)\end{array}$ & $\begin{array}{c}\text { Similarity } \\
(\%)\end{array}$ & $\begin{array}{l}\text { Gap } \\
(\%)\end{array}$ & Accession No. & Remark \\
\hline Pseudomonas sp. ND137 & 97.7 & 98.6 & 0.0 & BAB79291.1 & Uncharacterized \\
\hline Gilvimarinus polysaccharolyticus & 91.2 & 96.1 & 0.0 & WP_049721016.1 & Uncharacterized \\
\hline Catenovulum agarivorans YM01 & 54.4 & 70.5 & 4.8 & AGU13985.1 & Characterized \\
\hline Bacteroides plebeius DSM 17135 & 34.9 & 43.3 & 36.9 & EDY95404.1 & Characterized \\
\hline Microbulbifer agarilyticus & 32.7 & 44.0 & 34.4 & BAE06228.1 & Characteriaed \\
\hline
\end{tabular}




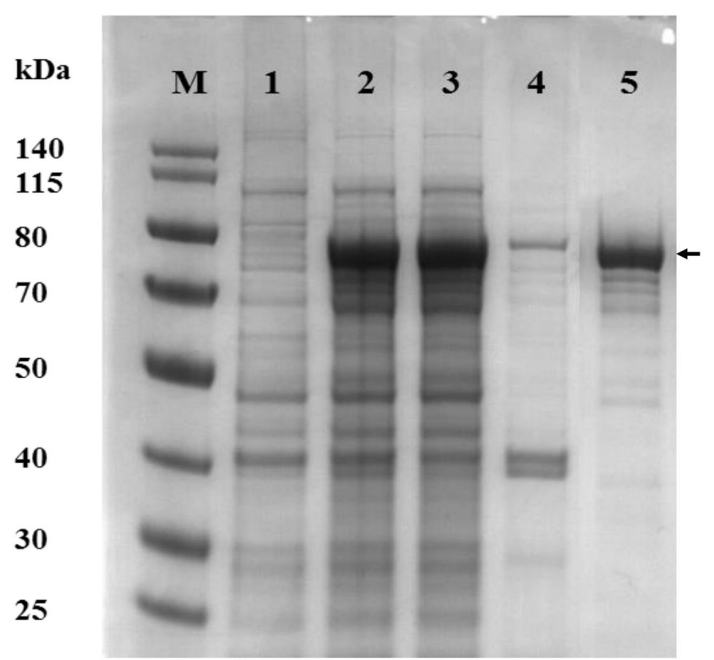

Fig. 1. SDS-PAGE analysis of purified rGaa16A.

M: Molecular weight marker; Lane 1: whole-cell lysates before induction; lane 2: whole-cell lysates after induction; lane 3: soluble fraction after cell lysis; lane 4: insoluble fraction after cell lysis; lane 5: purified rGaa16A.

optimum $\mathrm{pH}$ of rGaa16A was 7 (Fig. 2B). The activity of the enzyme increased gradually from $\mathrm{pH} 5$ to 7 , and it then dramatically decreased at $\mathrm{pH} 10$. The thermostability of rGaa16A is shown in Figs. 2C and 2D; rGaa16A was stable with over $80 \%$ of its activity after pre-incubation at $50^{\circ} \mathrm{C}$ for $60 \mathrm{~min}$. However, it showed low stability, retaining less than $50 \%$ of its activity at $55^{\circ} \mathrm{C}$ after preincubation for $30 \mathrm{~min}$. Interestingly, the thermostability of rGaa16A was improved in the presence of $\mathrm{CaCl}_{2}$. The effects of metal ions, salts, and chelators on rGaa16A activity are shown in Fig. 3. The activity of rGaa16A was significantly inhibited by $\mathrm{CuSO}_{4}$, and $\mathrm{ZnSO}_{4}$, whereas its activity was enhanced by $\mathrm{CaCl}_{2}, \mathrm{MnCl}_{2}, \mathrm{NaCl}$, and $\mathrm{FeSO}_{4}$.

The specific activity of rGaa16A is shown in Table 3. rGaa16A exhibited specific activity toward agarose at 103.5 U/mg. rGaa16A maintained its activity well in the presence of $\mathrm{CaCl}_{2}$. In the absence of $\mathrm{CaCl}_{2}, \mathrm{rGaa} \mathrm{A} \mathrm{A}$ activity was only 63 and $67 \mathrm{U} / \mathrm{mg}$ at $50^{\circ} \mathrm{C}$ and $60^{\circ} \mathrm{C}$, respectively. Meanwhile, it was 101.5 and $84.3 \mathrm{U} / \mathrm{mg}$ at $50^{\circ} \mathrm{C}$ and $60^{\circ} \mathrm{C}$, respectively, in the presence of $\mathrm{CaCl}_{2}$.

\section{Hydrolysis Product of rGaa16A}

The enzyme reaction products of rGaa16A were identified using TLC, which revealed that rGaa16A catalyzed the rapid degradation of agar to neoagarotetraose (NA4),
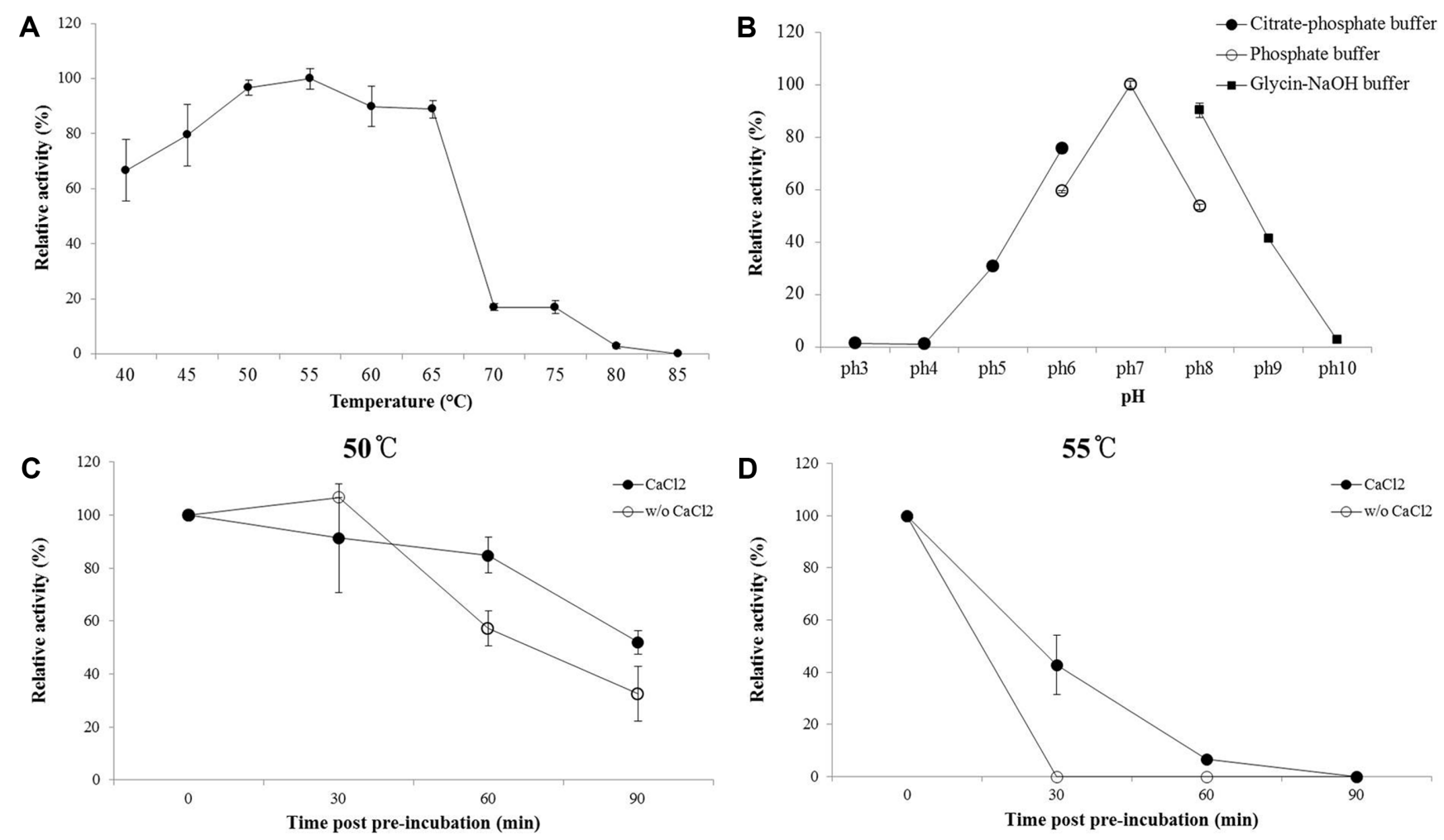

Fig. 2. Biochemical properties of rGaa16A.

Optimum temperature (A), optimum $\mathrm{pH}(\mathbf{B})$, and thermal stability at $50^{\circ} \mathrm{C}(\mathbf{C})$ and at $55^{\circ} \mathrm{C}(\mathbf{D})$. 


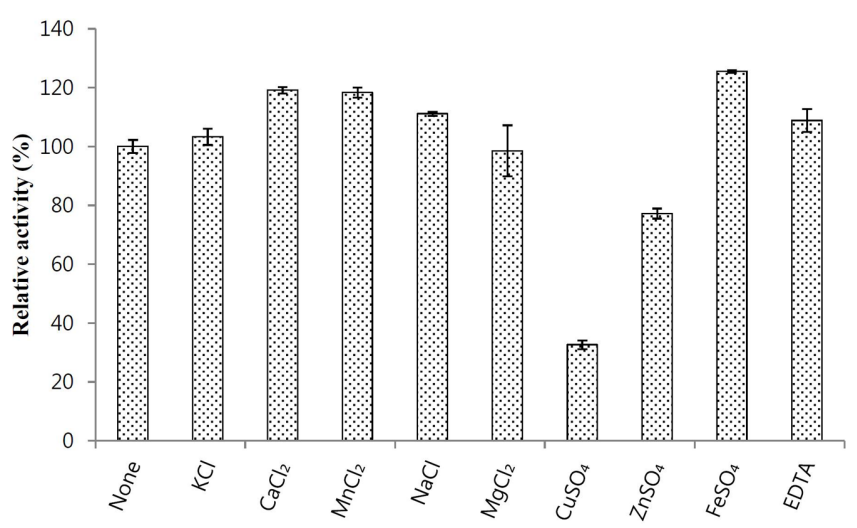

Fig. 3. Effects of chemicals and metal ions on the agarolytic activity of rGaa16A.

neoagarohexaose (NA6), neoagaro-oligosaccharides, and neoagaro-oligosaccharides larger than NA8 as products of the early stage of the reaction (Fig. 4A). After $60 \mathrm{~min}$ of incubation, NA4 and NA6, as well as trace amounts of compounds larger than NA8, were present. Finally, only NA4 was observed after overnight incubation (Fig. 4B).

\section{Discussion}

The purpose of this study was to molecularly characterize
Table 3. Specific activity of rGaa16A.

\begin{tabular}{ccc}
\hline \multirow{2}{*}{ Temp } & \multicolumn{2}{c}{ Specific activity $(\mathrm{Unit} / \mathrm{mg}, \mu \mathrm{mol} / \mathrm{mg} / \mathrm{min})$} \\
\cline { 2 - 3 } & rGaa16A & rGaa16A $+\mathrm{CaCl}_{2}$ \\
\hline $50^{\circ} \mathrm{C}$ & $63.1 \pm 7.5$ & $101.5 \pm 5.1$ \\
$55^{\circ} \mathrm{C}$ & $103.5 \pm 5.9$ & $102.7 \pm 3.7$ \\
$60^{\circ} \mathrm{C}$ & $67.9 \pm 6.8$ & $84.3 \pm 0.7$ \\
\hline
\end{tabular}

The specific activity was analyzed at $50^{\circ} \mathrm{C}, 55^{\circ} \mathrm{C}$, and $60^{\circ} \mathrm{C}$ in the presence and absence of $\mathrm{CaCl}_{2}$.

and analyze the biochemical properties of a new $\beta$-agarase identified in G. agarilyticus JEA5, the first report of such an enzyme isolated from the genus Gilvimarinus. The genomic DNA sequence was obtained from G. agarilyticus JEA5 using NGS technology. The amino acid sequence of Gaa16A has features typical of GH16 family $\beta$-agarases, such as a GH16 domain and RICIN superfamily domain, known to be a carbohydrate recognition region. The presence of RICIN improves functional capabilities, such as enzymatic activity, inhibitory toxicity, and signal transduction. This domain has been shown in some instances to bind simple sugars, such as galactose or lactose [36, 37]. Most GH16 $\beta$-agarases consist of two main functional domains GH16 catalytic domain and carbohydrate-binding module 6, but the RICIN superfamily in the C-terminal region also has been reported from some GH16 family $\beta$-agarases, such as
A

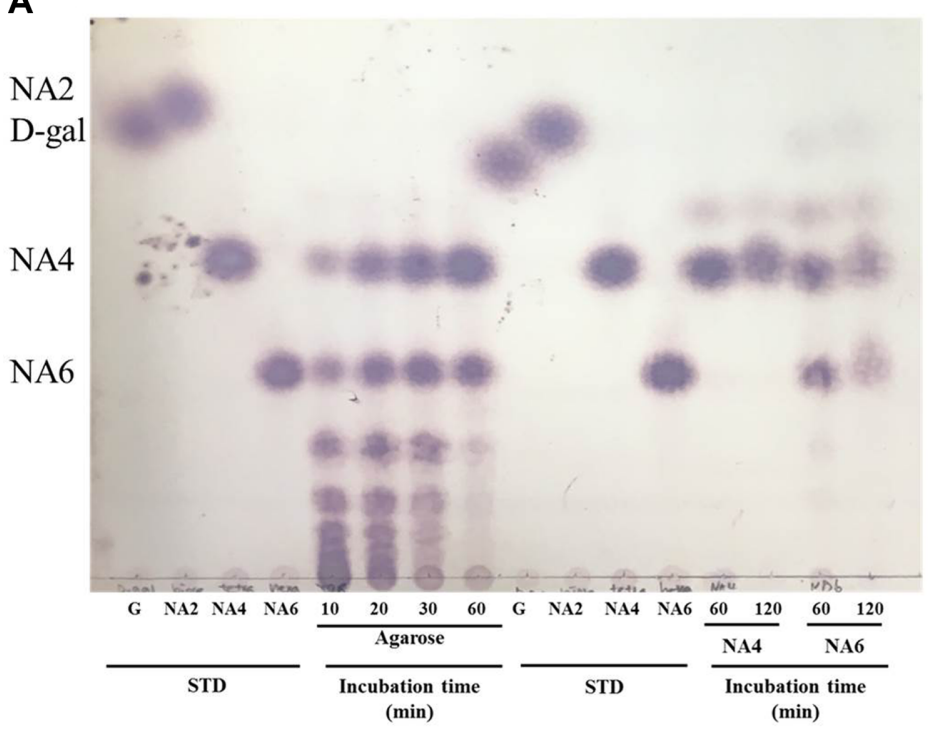

B

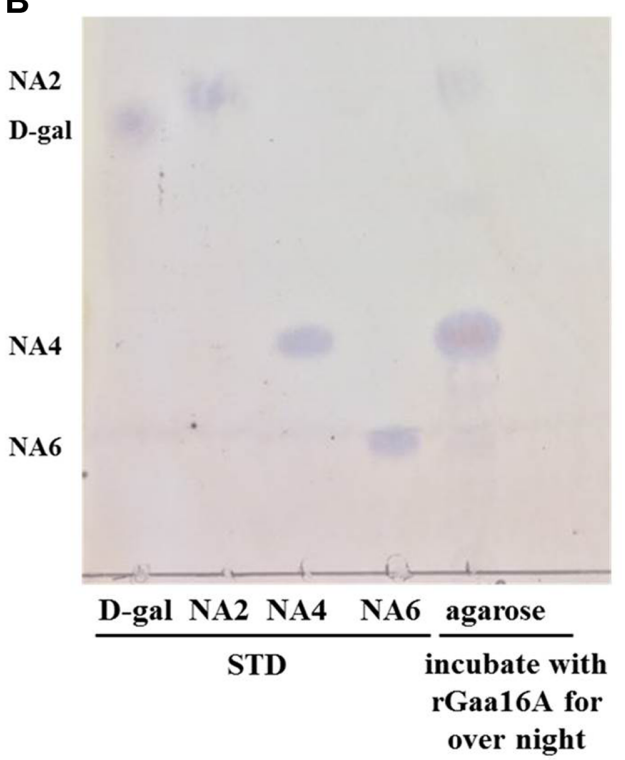

Fig. 4. TLC analysis of the rGaa16A enzyme hydrolysis products from agarose and neogaro-oligosaccharides.

The hydrolytic products of rGaa16A activity toward agarose for 10, 20, 30, and $60 \mathrm{~min}$, and neoagaro-oligosaccharides for 60 and $120 \mathrm{~min}$ (A) and hydrolytic product after overnight (B) were developed in silica gel 60 plate. D-Galactose (G), neoagarobiose (NA2), neoagarotetraose (NA4), and neogarohexaose (NA6) were used as standards (STD). 
YM01-3 from Catenovulum agarivorans YM01T [38], AgaH92 from Pseudoalteromonas sp. H9 [39], and AgaV from Vibrio sp. V134 [40].

Full-length rGaa16A without the signal peptide and two truncated derivatives (including the carbohydrate-binding module and a sequence without RICIN) were expressed in E. coli. The carbohydrate-binding region (RICIN domain) of recombinant agarase exhibited low agarolytic activity (data not shown), whereas high agarolytic activity was observed when recombinant agarase was overexpressed without the RICIN region. This result is similar to the behavior of agarase AgaD from the marine bacterium Vibrio sp. strain PO-303 [41]. rAgaD containing only the catalytic module without the carbohydrate-binding module (CBM) also showed higher agarolytic activity than CBMcontaining recombinant AgaD.

The optimum temperature of rGaa16A was observed at $55^{\circ} \mathrm{C}$, which was higher than the gelling temperature of agar $\left(>40^{\circ} \mathrm{C}\right)$, and the activity of rGaa16A was retained at $50^{\circ} \mathrm{C}$ after preincubation for $90 \mathrm{~min}$. The ability of an enzyme to convert agar into oligosaccharide while maintaining high catalytic activity and thermostability at temperatures above the gelling temperature may be advantageous for different applications. Tightly arranged bundles of gelled agar obstruct enzymatic degradation; therefore, other known agarases also show optimum temperatures that are higher than the gelling temperature $[4,19]$. The optimum $\mathrm{pH}$ of rGaa16A was neutral. This result is similar to previous reports for marine-derived agarases. Although a few agarases, such as AgaC from Vibrio sp. PO-303 and AgaB from Pseudoalteromonas sp. CY24, have been reported to have optimum activity at $\mathrm{pH} 6.5$ and 5.5 , respectively $[42,43]$, most agarases exhibit maximum activity at a neutral or a weakly alkaline $\mathrm{pH}$ [2]. It is well known that natural seawater has a weakly alkaline $\mathrm{pH}$. For these reasons, marine-derived agarases typically exhibit optimal activity under neutral or weakly alkaline conditions.

The activity of rGaa16A increased in the presence of $2.5 \mathrm{mM} \mathrm{CaCl}_{2}$. Additionally, in the specific activity test, we found that rGaa16A maintained its activity well at a high temperature of $60^{\circ} \mathrm{C}$ (Table 3) in the presence of $\mathrm{CaCl}_{2}$. The amino acid sequence of Gaa16A contains three predicted calcium-binding sites. Several studies have reported that $\mathrm{CaCl}_{2}$ is not involved in the catalytic machinery, but it has been shown to have a stabilizing effect in family GH16. However, in our study, the presence of calcium ions had a significant effect on rGaa16A activity (approximately 19\% increase) and strongly enhanced the thermostability of rGaa16A.
Agarases belonging to the same GH family exhibit similar patterns of agarose degradation. The end product or main product is NA4 for most reported GH16 $\beta$-agarases [2]. rGaa16A also hydrolyzed agarose to NA4, similar to results reported previously for GH16 family agarases. NA4 exhibited several bioactivities, such as a whitening effect [44], antioxidative activity, a prebiotic effect [45], and an anti-inflammatory effect [46].

In conclusion, a GH16 family $\beta$-agarase gene (gaa16a) was isolated from the draft genome sequence of the marine bacterium G. agarilyticus JEA5. The recombinant $\beta$-agarase (rGaa16A) was overexpressed and purified, and its biochemical properties were analyzed, representing the first agarase characterized from the genus Gilvimarinus. rGaa16A was stable at temperatures below $50^{\circ} \mathrm{C}$, and the optimum temperature was higher than the gelling temperature of agar. Moreover, its activity and stability were improved in the presence of $\mathrm{CaCl}_{2}$. $\mathrm{rGaa} 16 \mathrm{~A}$ hydrolyzed agarose to NA4, which has diverse physiological and biological activities with great economic value. Therefore, this enzyme can be used for different industrial applications, such as in the cosmetic, pharmaceutical, and food industries.

\section{Acknowledgments}

This research was supported by collective research grants from the Korea Institute of Ocean Science \& Technology (PE0129C) and "Development of integrated technologies for developing biomaterials using by magma seawater" (20170326) funded by the Ministry of Ocean and Fisheries, Korea.

\section{Conflict of Interest}

The authors have no financial conflicts of interest to declare.

\section{References}

1. Chi WJ, Chang YK, Hong SK. 2012. Agar degradation by microorganisms and agar-degrading enzymes. Appl. Microbiol. Biotechnol. 94: 917-930.

2. Fu XT, Kim SM. 2010. Agarase: review of major sources, categories, purification method, enzyme characteristics and applications. Mar. Drugs 8: 200-218.

3. Araki C. 1956. Structure of the agarose constituent of agaragar. Bull. Chem. Soc. Jpn. 29: 543-544.

4. Mai Z, Su H, Zhang S. 2016. Isolation and characterization of a glycosyl hydrolase family 16 beta-agarase from a mangrove soil metagenomic library. Int. J. Mol. Sci. 17: E1360. 
5. Kobayashi R, Takisada M, Suzuki T, Kirimura K, Usami S. 1997. Neoagarobiose as a novel moisturizer with whitening effect. Biosci. Biotechnol. Biochem. 61: 162-163.

6. Yun EJ, Lee S, Kim JH, Kim BB, Kim HT, Lee SH, et al. 2013. Enzymatic production of 3,6-anhydro-L-galactose from agarose and its purification and in vitro skin whitening and anti-inflammatory activities. Appl. Microbiol. Biotechnol. 97: 2961-2970.

7. Yoshizawa Y, Ametani A, Tsunehiro J, Nomura K, Itoh M, Fukui $\mathrm{F}$, et al. 1995. Macrophage stimulation activity of the polysaccharide fraction from a marine alga (Porphyra yezoensis): structure-function relationships and improved solubility. Biosci. Biotechnol. Biochem. 59: 1933-1937.

8. Fernandez LE, Valiente OG, Mainardi V, Bello JL, Velez H, Rosado A. 1989. Isolation and characterization of an antitumor active agar-type polysaccharide of Gracilaria dominguensis. Carbohydr. Res. 190: 77-83.

9. Hu B, Gong Q, Wang Y, Ma Y, Li J, Yu W. 2006. Prebiotic effects of neoagaro-oligosaccharides prepared by enzymatic hydrolysis of agarose. Anaerobe 12: 260-266.

10. Jang M-K, Lee OKH, Yoo KH, Lee D-G, Lee S-H. 2007. Secretory overexpression of $\beta$-agarase in Bacillus subtilis and antibacterial activity of enzymatic products. J. Life Sci. 17: 1601-1604.

11. $\mathrm{Fu} \mathrm{XT}$, Pan CH, Lin H, Kim SM. 2009. Gene cloning, expression, and characterization of a beta-agarase, agaB34, from Agarivorans albus YKW-34. J. Microbiol. Biotechnol. 19: 257-264.

12. Leon O, Quintana L, Peruzzo G, Slebe JC. 1992. Purification and properties of an extracellular agarase from Alteromonas sp. strain C-1. Appl. Environ. Microbiol. 58: 4060-4063.

13. Ha JC, Kim GT, Kim SK, Oh TK, Yu JH, Kong IS. 1997. beta-agarase from Pseudomonas sp. W7: purification of the recombinant enzyme from Escherichia coli and the effects of salt on its activity. Biotechnol. Appl. Biochem. 26: 1-6.

14. Lee S, Park J, Yoon S, Kim J, Kong I. 2000. Sequence analysis of a beta-agarase gene (pjaA) from Pseudomonas sp. isolated from marine environment. J. Biosci. Bioeng. 89: 485-488.

15. Sugano Y, Matsumoto T, Kodama H, Noma M. 1993. Cloning and sequencing of agaA, a unique agarase 0107 gene from a marine bacterium, Vibrio sp. strain JT0107. Appl. Environ. Microbiol. 59: 3750-3756.

16. Sugano Y, Terada I, Arita M, Noma M, Matsumoto T. 1993. Purification and characterization of a new agarase from a marine bacterium, Vibrio sp. strain JT0107. Appl. Environ. Microbiol. 59: 1549-1554.

17. Oh C, Nikapitiya C, Lee Y, Whang I, Kim SJ, Kang DH, et al. 2010. Cloning, purification and biochemical characterization of beta agarase from the marine bacterium Pseudoalteromonas sp. AG4. J. Ind. Microbiol. Biotechnol. 37: 483-494.

18. Suzuki H, Sawai Y, Suzuki T, Kawai K. 2003. Purification and characterization of an extracellular $\beta$-agarase from Bacillus sp. MK03. J. Biosci. Bioeng. 95: 328-334.
19. Li J, Sha Y, Seswita-Zilda D, Hu Q, He P. 2014. Purification and characterization of thermostable agarase from Bacillus sp. BI-3, a thermophilic bacterium isolated from hot spring. J. Microbiol. Biotechnol. 24: 19-25.

20. Ohta Y, Hatada Y, Nogi Y, Li Z, Ito S, Horikoshi K. 2004. Cloning, expression, and characterization of a glycoside hydrolase family 86 beta-agarase from a deep-sea Microbulbiferlike isolate. Appl. Microbiol. Biotechnol. 66: 266-275.

21. Kim DK, Jang YR, Kim KH, Lee MN, Kim AR, Jo EJ, et al. 2011. Isolation and culture properties of a thermophilic agarase-producing strain, Microbulbifer sp. SD-1. Fish. Aquat. Sci. 14: 186-191.

22. Lee Y, Oh C, De Zoysa M, Kim H, Wickramaarachchi WD, Whang I, et al. 2013. Molecular cloning, overexpression, and enzymatic characterization of glycosyl hydrolase family 16 beta-agarase from marine bacterium Saccharophagus sp. AG21 in Escherichia coli. J. Microbiol. Biotechnol. 23: 913-922.

23. Lakshmikanth M, Manohar S, Lalitha J. 2009. Purification and characterization of $\beta$-agarase from agar-liquefying soil bacterium, Acinetobacter sp., AG LSL-1. Process Biochem. 44: 999-1003.

24. Du ZJ, Zhang DC, Liu SN, Chen JX, Tian XL, Zhang ZN, et al. 2009. Gilvimarinus chinensis gen. nov., sp. nov., an agar-digesting marine bacterium within the class Gammaproteobacteria isolated from coastal seawater in Qingdao, China. Int. J. System. Evol. Microbiol. 59: 2987-2990.

25. Cheng H, Zhang S, Huo YY, Jiang XW, Zhang XQ, Pan J, et al. 2015. Gilvimarinus polysaccharolyticus sp. nov., an agardigesting bacterium isolated from seaweed, and emended description of the genus Gilvimarinus. Int. J. System. Evol. Microbiol. 65: 562-569.

26. Kim BC, Kim MN, Lee KH, Kim HS, Min SR, Shin KS. 2011. Gilvimarinus agarilyticus sp. nov., a new agar-degrading bacterium isolated from the seashore of Jeju Island. Antonie Van Leeuwenhoek 100: 67-73.

27. Lee Y, Lee SJ, Park GH, Heo SJ, Umasuthan N, Kang DH, et al. 2015. Draft genome of agar-degrading marine bacterium Gilvimarinus agarilyticus JEA5. Mar. Genomics 21: 13-14.

28. Altschul SF, Gish W, Miller W, Myers EW, Lipman DJ. 1990. Basic local alignment search tool. J. Mol. Biol. 215: 403-410.

29. Petersen TN, Brunak S, von Heijne G, Nielsen H. 2011. SignalP 4.0: discriminating signal peptides from transmembrane regions. Nat. Methods 8: 785-786.

30. Larkin MA, Blackshields G, Brown NP, Chenna R, McGettigan PA, McWilliam H, et al. 2007. Clustal W and Clustal X version 2.0. Bioinformatics 23: 2947-2948.

31. Marchler-Bauer A, Lu S, Anderson JB, Chitsaz F, Derbyshire MK, DeWeese-Scott C, et al. 2011. CDD: a Conserved Domain Database for the functional annotation of proteins. Nucleic Acids Res. 39: D225-D229.

32. Letunic I, Doerks T, Bork P. 2012. SMART 7: recent updates to the protein domain annotation resource. Nucleic Acids Res. 40: D302-D305. 
33. Finn RD, Attwood TK, Babbitt PC, Bateman A, Bork P, Bridge AJ, et al. 2017. InterPro in 2017 - beyond protein family and domain annotations. Nucleic Acids Res. 45: D190-D199.

34. Jones P, Binns D, Chang HY, Fraser M, Li W, McAnulla C, et al. 2014. InterProScan 5: genome-scale protein function classification. Bioinformatics 30: 1236-1240.

35. Sumner JB. 1924. The estimation of sugar in diabetic urine, using dinitrosalicylic acid. J. Biol. Chem. 62: 287-290.

36. Swimmer C, Lehar SM, McCafferty J, Chiswell DJ, Blattler WA, Guild BC. 1992. Phage display of ricin B chain and its single binding domains: system for screening galactosebinding mutants. Proc. Natl. Acad. Sci. USA 89: 3756-3760.

37. Dodd RB, Drickamer K. 2001. Lectin-like proteins in model organisms: implications for evolution of carbohydrate-binding activity. Glycobiology 11: 71R-79R.

38. Cui F, Dong S, Shi X, Zhao X, Zhang XH. 2014. Overexpression and characterization of a novel thermostable beta-agarase YM01-3, from marine bacterium Catenovulum agarivorans YM01(T). Mar. Drugs 12: 2731-2747.

39. Chi WJ, Lee CR, Dugerjonjuu S, Park JS, Kang DK, Hong SK. 2015. Biochemical characterization of a novel iron-dependent GH16 beta-agarase, AgaH92, from an agarolytic bacterium Pseudoalteromonas sp. H9. FEMS Microbiol. Lett. 362: fnv035.

40. Zhang WW, Sun L. 2007. Cloning, characterization, and molecular application of a beta-agarase gene from Vibrio sp. strain V134. Appl. Environ. Microbiol. 73: 2825-2831.

41. Dong J, Tamaru Y, Araki T. 2007. Molecular cloning, expression, and characterization of a beta-agarase gene, agaD, from a marine bacterium, Vibrio sp. strain PO-303. Biosci. Biotechnol. Biochem. 71: 38-46.

42. Dong J, Hashikawa S, Konishi T, Tamaru Y, Araki T. 2006. Cloning of the novel gene encoding beta-agarase $\mathrm{C}$ from a marine bacterium, Vibrio sp. strain PO-303, and characterization of the gene product. Appl. Environ. Microbiol. 72: 6399-6401.

43. Ma C, Lu X, Shi C, Li J, Gu Y, Ma Y, et al. 2007. Molecular cloning and characterization of a novel beta-agarase, AgaB, from marine Pseudoalteromonas sp. CY24. J. Biol. Chem. 282: 3747-3754.

44. Jang MK, Lee DG, Kim NY, Yu KH, Jang HJ, Lee SW, et al. 2009. Purification and characterization of neoagarotetraose from hydrolyzed agar. J. Microbiol. Biotechnol. 19: 1197-1200.

45. Zhang N, Mao X, Li RW, Hou E, Wang Y, Xue C, et al. 2017. Neoagarotetraose protects mice against intense exercise-induced fatigue damage by modulating gut microbial composition and function. Mol. Nutr. Food Res. 61: DOI: 10.1002/mnfr. 201600585.

46. Wang W, Liu P, Hao C, Wu L, Wan W, Mao X. 2017. Neoagaro-oligosaccharide monomers inhibit inflammation in LPS-stimulated macrophages through suppression of MAPK and NF-кB pathways. Sci. Rep. 7: 44252. 